\title{
Behavioral and Electrophysiological Assessment of Adults Who Underwent Cochlear Implantation After Hearing Aid Experience*
}

Victor Goiris Calderaro ${ }^{10}$ Maria Stella Arantes do Amaral ${ }^{2}$ Benedita Aparecida Borges da Luz $^{2}$ Sarah Carolina Bernal ${ }^{1}$ Miguel Ângelo Hyppolito ${ }^{3}$ Ana Claudia Mirândola Barbosa Reis ${ }^{1}$

\author{
${ }^{1}$ Department of Ophthalmology, Otolaryngology and Head and Neck \\ Surgery/Speech-Language Pathology and Audiology Division, \\ Faculdade de Medicina de Ribeirão Preto, Universidade de São Paulo, \\ Ribeirão Preto, SP, Brazil \\ 2 Hospital das Clínicas, Faculdade de Medicina de Ribeirão Preto, \\ Universidade de São Paulo, Ribeirão Preto, SP, Brazil \\ ${ }^{3}$ Department of Ophthalmology, Otolaryngology and Head and Neck \\ Surgery, Faculdade de Medicina de Ribeirão Preto, Universidade de \\ São Paulo, Ribeirão Preto, SP, Brazil
}

Int Arch Otorhinolaryngol 2020;24:e132-e139.
Address for correspondence Victor Goiris Calderaro, Master degree student, Departamento de Ciências da Saúde, Faculdade de Medicina de Ribeirão Preto - Universidade de São Paulo. Bandeirantes Avenue, 3900, Ribeirão Preto, SP, 14049-900, Brazil (e-mail: victor.calderaro@usp.br).

\author{
Abstract \\ Keywords \\ - event-related \\ potentials \\ - P300 \\ - cochlear implantation \\ - adult \\ - hearing loss
}

Introduction Cochlear implantation has been considered a viable option to restore hearing perception in adults with severe to profound postlingual hearing loss.

Objectives To analyze behavioral hearing responses and P300 latency and amplitude measurements in adults with bilateral sensorineural hearing loss at two phases, first when they were using hearing aids (HAs) and, then, after 12 months of cochlear implant (Cl) use. The association between behavioral and electrophysiological evaluations was explored, as it is believed that the study of auditory processing with different hearing devices can contribute to future $\mathrm{Cl}$ adjustments and fittings, especially for patients who cannot give subjective feedback (such as small children and individuals with multiple disabilities).

Methods Prospective comparative study (Ethical approval 11489/2014). Twelve adults were assessed, 7 males and 5 females, in the 22 to 76 years old age range, who had undergone $\mathrm{Cl}$ surgery after $\mathrm{HA}$ experience.

Results The analyses showed an improvement of hearing thresholds when patients started using Cls. Comparing data from P300 latency measurements, there was an increase of the P300 wave post- $\mathrm{Cl}$ at $\mathrm{Cz}$ and $\mathrm{Fz}$. Regarding the amplitude, P300 mean values decreased at $\mathrm{Cz}$, but increased at $\mathrm{Fz}$. There was no significant correlation between behavioral and electrophysiological assessment and the variables age, gender, auditory deprivation, and electronic device used.

Conclusion There was a significant improvement of hearing thresholds after twelve months of $\mathrm{Cl}$ experience. The mean latency values of P300 after 12 months of $\mathrm{Cl}$ use increased at $\mathrm{Cz}$ and $\mathrm{Fz}$, while mean amplitude values decreased at $\mathrm{CZ}$ and increased at $\mathrm{Fz}$.

\footnotetext{
This paper was presented in: $31^{\circ}$ Encontro Internacional de Audiologia - São Paulo, SP, Brasil.
}

received

February 17, 2019

accepted

June 20, 2019
DOI https://doi.org/

10.1055/s-0039-1695022. ISSN 1809-9777.
Copyright $\odot 2020$ by Thieme Revinter

Publicações Ltda, Rio de Janeiro, Brazil
License terms

(c) $(1) \$$ 


\section{Introduction}

Individuals with severe to profound hearing loss are known to receive little to no benefit with the use of hearing aids (HAs). In those cases, cochlear implants (CIs) are an efficient alternative, which can provide a high speech recognition rate. ${ }^{1}$

This device projects sound to be received by a microphone and be sent to a speech processor, which digitally codifies speech through different strategies that vary according to the device's manufacturer. Signal is then sent by a transmitter to an internal stimulator, which converts signal into electrical impulses sent to electrodes inside of the cochlea. Thus, electrodes stimulate the cochlear nerve, and impulses can travel along the auditory system. ${ }^{2}$

Currently, there is a need to determine audiological parameters for $\mathrm{Cl}$ indication and, especially, for patients' follow-up. Behavioral assessment of $\mathrm{Cl}$ patients, through speech perception tests and self-assessment questionnaires, has been a common procedure; however, there is a concern presented by audiologists regarding objective assessments, specifically electrophysiological tests, aiming to investigate the central auditory nervous system (CANS). Auditory evoked potentials, particularly cognitive ones, which are obtained by recording and measuring responses to sensorial stimuli captured on the cranial surface, have been under investigation, with the purpose of investigating possible changes in the CANS, such as neural plasticity, after CI stimulation.

Among other cognitive auditory evoked potentials, P300 provides a neurophysiological assessment of cognitive function, since it is evoked by the conscious interaction between the hearing system and the somatosensory cortex, and it depends on the attention and participation of the subject to elaborate responses. ${ }^{3,4}$ The P300 data are collected through random presentations of a rare acoustic stimulus previously established among other frequent stimuli ("oddball" paradigm). The endogenous perception of rare stimuli will provide necessary data for the elicitation of waves. The analyzed waves can bring information on the treatment of hearing disorders and reflect on the electrophysiological activity involved during attention, discrimination, memory, integration and decision-making abilities. ${ }^{5}$

The P300 is included in the long latency auditory evoked potentials (LLAEPs), which can be observed approximately between 80 and $700 \mathrm{~ms}$ after an acoustic stimulus presentation. ${ }^{6}$ Studies show a wide variety of amplitude values for this potential, which can vary according to task and attention.

The P300 has been tested with the $\mathrm{CI}$ population and is gradually being included in clinical practice. Studies have measured P300 waves in children and adults with HAs and CIs, showing that this kind of research is viable; however, more studies with P300 in adult CI users are needed to demonstrate its applicability. ${ }^{7-10}$ Hopefully, the results obtained in this study can contribute, along with behavioral tests, as sensitive indicators of the processing functions in these patients and therefore help us in the assessment of $\mathrm{CI}$ candidates.

Thus, the aim of this study was to analyze the auditory behavioral and electrophysiological responses, latency and amplitude values of the P300 potential, in adults with bilateral profound sensorineural hearing loss, HA users submitted to cochlear implantation.

\section{Methods}

The present study is a transversal prospective comparative and correlational one, with emphasis on diagnostic research.

The project was approved by the Institutional Review Board (IRB), ethical approval 11489/2014, CAE number 32404514.9.0000.5440 (Doc. 1.255.971).

\section{Participants}

Twelve adults participated in the present study, seven male and five female. To fulfill the inclusion criteria, subjects were required to have bilateral postlingual sensorineural hearing loss and be submitted to CIs after bilateral HA experience.

\section{Procedures}

Data were collected in two phases. The $1^{\text {st }}$ one was prior to $\mathrm{CI}$ surgery, when the subjects were using HAs, and the $2^{\text {nd }}$ one was at least 12 months after $\mathrm{Cl}$ activation. Both phases were performed in the same conditions.

In the hearing health program where this study was conducted, the audiological assessment of $\mathrm{Cl}$ candidates investigates their hearing and language conditions, and consists of the following procedures: pure tone audiometry and speech perception tests with supra-aural earphones, electrophysiological assessment (brainstem evoked response audiometry and cortical auditory evoked potentials-P300), as well as audiometry and speech perception tests in free field, with HAs.

On the $2^{\text {nd }}$ phase, participants were reevaluated with puretone audiometry and $\mathrm{P} 300$. Audiometry was performed in free field, with the AC 40 audiometer (Interacoustics, Middelfart, Denmark), considering frequencies from 250 to $8,000 \mathrm{~Hz}$, and the subject was seated, in an acoustically treated environment.

Mean hearing thresholds were calculated by the following frequencies: 500, 1,000, 2,000 e 4,000 Hz.

To obtain P300 measures, the two-channel Bio-logic equipment (Navigator ${ }^{\circledR}$ Pro from Bio-logic ${ }^{\circledR}$ Systems Corp. Auditory Evoked Potential - AEPSystem, 1.3.0 version/Natus Medical, USA), connected to a conventional computer, was used to register the auditory evoked potentials. Active electrodes were positioned at $\mathrm{Cz}$ and $\mathrm{Fz}$, connected to entry 1 of the preamplifier; channels 1 and 2. Reference electrodes were connected to entry 2 of channels 1 and 2 (jumper), from the preamplifier and placed on the left earlobe (A1). The earth electrode was placed on the right earlobe (A2). While testing, the individual impedance of electrodes was maintained at $5 \mathrm{~K} \Omega$ or less, and the difference of impedance between them at $3 \mathrm{~K} \Omega$ or less. The time window was shown as $512 \mathrm{~ms}$, with a $50,000 \mu \mathrm{V}$ gain, high-pass filters of $30 \mathrm{~Hz}$ and low pass of $100 \mathrm{~Hz}$.

During the procedure, the subjects were in a semi-seated position, with their eyes open and fixed on a target point in front of them, to avoid eye movement artifacts. Tone bursts were chosen as auditory stimuli, with a frequency of $1,000 \mathrm{~Hz}$ for the frequent stimulus and $2,000 \mathrm{~Hz}$ for the rare stimulus, 
Table 1 Characterization of subjects' audiological variables without the use of electronic hearing devices

\begin{tabular}{|l|l|l|l|l|l|}
\hline Audiological Variables & Mean & Median & SD & Minimum & Maximum \\
\hline Age at hearing loss (years) & 18.08 & 10.00 & 16.78 & 0.00 & 49.00 \\
\hline Auditory deprivation time (years) & 8.79 & 3.50 & 13.73 & 0.00 & 46.00 \\
\hline Age at HA fitting (years) & 26.58 & 23.00 & 18.00 & 1.00 & 53.00 \\
\hline HA use time (years) & 19.54 & 18.50 & 14.64 & 0.42 & 47.00 \\
\hline Average RE HT without HAs (dB HL) & 110.55 & 112.00 & 9.02 & 85.00 & 118.00 \\
\hline Average LE HT without HAs (dB HL) & 109.25 & 115.50 & 11.38 & 80.00 & 119.00 \\
\hline RE SPT results without HAs (\%) & 33.00 & 0.00 & 45.99 & 0.00 & 100.00 \\
\hline LE SPT results without HAs (\%) & 32.00 & 0.00 & 45.00 & 0.00 & 100.00 \\
\hline
\end{tabular}

Abbreviations: dB HL, decibel hearing level; HA, hearing aid; HT, hearing thresholds; LE, left ear; RE, right ear; SD, standard deviation; SPT, speech perception test.

where $80 \%$ were frequent stimuli and $20 \%$ were rare stimuli, randomly presented, at an intensity of $90 \mathrm{~dB}$. Measurements were taken in two successive passages to allow good definition and replication.

The P300 testing took place in free field, with the loudspeaker positioned at an azimuthal angle of $0^{\circ}$ when subjects had bilateral HAs, and at $45^{\circ}$ when subjects were then using a $\mathrm{Cl}$, positioned next to the speech processor, at a $60 \mathrm{~cm}$ distance.

For both phases, subjects were asked to identify the rare stimulus by slightly raising their index finger each time it appeared. Thus, behavioral responses in the presence of rare stimuli were observed and registered by the researchers to be then analyzed. ${ }^{6,11,12}$ Wave tracing registrations were considered when there was replication of the tracing and when the subject identified the stimulus with a maximum of $10 \%$ stimulus deviation ( $50 \pm 5$ stimuli). Before starting to register the responses, subjects were exposed to the stimuli and trained so that they fully understood the task.

Behavioral registrations were made by two observers, individually, with no communication between them and behaviors were categorized as:

- Immediate response to rare stimulus;

- Late response to rare stimulus (less than 2 seconds);

- Incompatible response (raises finger in the absence of rare stimuli);

Cochlear implant brand and model were not variables that could be controlled, considering the study's institutional demand of equal distribution among brands, since it is a service accredited to the Unified Health System (SUS, in the Portuguese acronym. Public health system that grants elec- tronic hearing devices, equally distributed by the accredited companies). ${ }^{13-15}$

\section{Sample Profile}

-Table 1 shows the audiological data of the 12 participants, in which we can see that 10 were unilateral CI users and 2 were binaural CI users. Six of the subjects received CI surgery on the right ear, and six on the left ear. The average age was 46.5 years old, considering that the lowest age was 22 , and the highest, 76 .

- Table 2 contains audiological data of the subjects during both phases of the study. Mean hearing thresholds with HAs when compared with mean hearing thresholds with $\mathrm{Cl}$ show a difference of $43.92 \mathrm{~dB} \mathrm{HL}$. It is noticeable that the highest mean hearing threshold with $\mathrm{CI}$ was $51 \mathrm{~dB} \mathrm{HL}$, which belongs to one subject who did not perceive benefits from $\mathrm{CI}$ use, unlike the rest of the group. Regarding the speech perception test (SPT) results, higher percentage scores can be seen when subjects were in the $\mathrm{CI}$ phase.

The non-identification of hearing loss etiology represents $50 \%$ of the 12 subjects, and otosclerosis is the most frequent etiology, whereas other causes (mumps, bacterial meningitis, ototoxicity and mechanical trauma) appeared only once.

About the $\mathrm{CI}$ brands used in this study, Med-El (Innsbruck, Austria) was the most frequent one, followed by Cochlear (Sydney, Australia) and Advanced Bionics (Norwest, Australia), each with 3 subjects. Lastly, there were 2 subjects with Neurelec (Vallarius, France) Advanced Bionics (Los Angeles, USA). Each device has its own functional characteristics, which are described in - Table 3.

Table 2 Characterization of Subjects' Audiological Variables with the Use of $\mathrm{HA}$ and $\mathrm{Cl}$

\begin{tabular}{|l|l|l|l|l|l|}
\hline Audiological variables & Mean & Median & SD & Minimum & Maximum \\
\hline Average HT with HAs (dB HL) & 75.25 & 73.50 & 16.33 & 50.00 & 96.00 \\
\hline Average HT with Cls (dB HL) & 31.33 & 29.00 & 8.85 & 17.00 & 51.00 \\
\hline Average SPT result with HAs (\%) & 28.20 & 9.00 & 34.49 & 0.00 & 80.00 \\
\hline Average SPT result with Cls (\%) & 68.42 & 81.50 & 34.54 & 0.00 & 100.00 \\
\hline
\end{tabular}

Abbreviations: $\mathrm{Cl}$, cochlear implant; $\mathrm{dB}$ HL, decibel hearing level; HA, hearing aid; HT, hearing thresholds; LE, left ear; RE, right ear; SD, standard deviation; SPT, speech perception test. 
Table 3 Characterization of cochlear implant devices used by the subjects of this sample $(n=12)$

\begin{tabular}{|l|l|l|l|l|l|}
\hline Subject & $\begin{array}{l}\text { Device } \\
\text { brand }\end{array}$ & $\begin{array}{l}\text { Number of } \\
\text { channels }(\boldsymbol{n})\end{array}$ & $\begin{array}{l}\text { Speech coding } \\
\text { strategies }\end{array}$ & $\begin{array}{l}\text { Pulse rate per } \\
\text { channel (pps) }\end{array}$ & Current (Hz) \\
\hline $\mathbf{1}$ & Med-El & 11 & FS4 & 802 & 87.08 \\
\hline $\mathbf{2}$ & Cochlear & 22 & ACE & 900 & 25 \\
\hline $\mathbf{3}$ & Neurelec & 24 & Crystalis XDP & 500 & - \\
\hline $\mathbf{4}$ & Med-El & 12 & FS4 & 705 & 17.92 \\
\hline $\mathbf{5}$ & Cochlear & 22 & ACE & 900 & 25 \\
\hline $\mathbf{6}$ & Ad. Bionics & 16 & Hires PWI Fidelity 120 & 3,712 & 18 \\
\hline $\mathbf{7}$ & Ad. Bionics & 16 & Hires S/Fidelity 120 & 3,712 & 18 \\
\hline $\mathbf{8}$ & Ad. Bionics & 16 & Hires P/Fidelity 120 & 2,652 & 26.9 \\
\hline $\mathbf{9}$ & Cochlear & 22 & ACE & 1,200 & 25 \\
\hline $\mathbf{1 0}$ & Med-El & 11 & FS4 & 802 & 40 \\
\hline $\mathbf{1 1}$ & Neurelec & 24 & Crystalis & 500 & - \\
\hline $\mathbf{1 2}$ & Med-El & 12 & FS4 & 750 & 50.42 \\
\hline
\end{tabular}

Abbreviations: Ad., Advanced; $\mathrm{Cl}$, Cochlear implant; Hz, hertz; n, number; pps, pulses per second.

\section{Data Analysis}

An exploratory analysis took place, to summarize values, organize and describe data in two ways: through tables with descriptive measures and through graphs. Continuous variables were expressed as basic descriptive statistics and categorical variables were expressed as frequency and percentage. To reach the established aims, a linear mixed-effects regression model and Pearson correlation coefficient ( $r$ ) were used. A significance level of $5 \%(p \leq 0.05)$ was adopted for all analyses and adjustments were obtained in the SAS software, version 9.2 (SAS Institute Inc., Cary, NC, USA).

\section{Results}

To verify the correlation between two quantitative variables, an analysis was performed through Pearson correlation coefficient $(r)$, as we can see in - Table 4 . There was a strong positive correlation when the following variables were correlated: subject's current age and age at hearing loss, current age and age when starting to use Has, and hearing loss onset age with the start of HA use. There was also a moderately negative relation between subject's age and mean hearing thresholds with $\mathrm{CI}$ after at least 12 months of use.

In the analysis of potentials N1, P2, N2 and P300, when correlated to the subject's gender, age, time of auditory deprivation, $\mathrm{CI}$ current $(\mathrm{Hz})$, pulses per second (pps) and mean hearing thresholds with HAs, there was no significant value. However, P300 latency values in both phases, when analyzed and related to $\mathrm{Cl}$ 's current, show an increase in latency $(p=0.0545)$.

-Figs. 1 and 2 show mean latency distributions for the N1 and P2 potentials (exogenous) and N2 and P300 (endogenous), respectively, in the different fixation positions of the electrodes $(\mathrm{Cz}$ and $\mathrm{Fz})$ related to the two phases of the research, while -Figs. $\mathbf{3}$ and $\mathbf{4}$ show the mean distributions

Table 4 Correlation between audiological variables

\begin{tabular}{|c|c|c|c|c|c|c|}
\hline \multicolumn{7}{|c|}{ Pearson correlation coefficient } \\
\hline \multicolumn{2}{|l|}{ Parameter } & $\begin{array}{l}\text { Age at } \\
\text { hearing loss }\end{array}$ & $\begin{array}{l}\text { Auditory } \\
\text { deprivation time }\end{array}$ & $\begin{array}{l}\text { Age at } \\
\text { HA fitting }\end{array}$ & $\begin{array}{l}\text { Average HT } \\
\text { with HA }\end{array}$ & $\begin{array}{l}\text { Average } \mathrm{HT} \\
\text { with } \mathrm{Cl}\end{array}$ \\
\hline \multirow[t]{2}{*}{ Current age } & Corr & $0.6526^{a}$ & 0.0611 & $0.6450^{\mathrm{a}}$ & 0.3062 & $-0.5912^{\mathrm{a}}$ \\
\hline & $p$-value & $0.0214^{\mathrm{b}}$ & 0.8502 & $0.0235^{b}$ & 0.3329 & $0.0429^{b}$ \\
\hline \multirow{2}{*}{$\begin{array}{l}\text { Age at } \\
\text { hearing } \\
\text { loss }\end{array}$} & Corr & - & -0.2025 & $0.6816^{a}$ & -0.1095 & -0.5220 \\
\hline & $p$-value & - & 0.6304 & $0.0146^{\mathrm{b}}$ & 0.7346 & 0.0817 \\
\hline \multirow{2}{*}{$\begin{array}{l}\text { Auditory } \\
\text { deprivation time }\end{array}$} & Corr & - & - & 0.4778 & 0.4289 & -0.0102 \\
\hline & $p$-value & - & - & 0.1161 & 0.1641 & 0.9748 \\
\hline \multirow[t]{2}{*}{ Age at $\mathrm{HA}$ fitting } & Corr & - & - & - & 0.1971 & -0.5078 \\
\hline & $p$-value & - & - & - & 0.5391 & 0.0919 \\
\hline
\end{tabular}

Abbreviations: $\mathrm{Cl}$, cochlear implant; Corr, correlation; $\mathrm{HA}$, hearing aid; $\mathrm{HT}$, hearing threshold.

${ }^{\mathrm{a}}$ Corr $\geq 40 \%$.

${ }^{\mathrm{b}} \mathrm{p}<0.05$. 


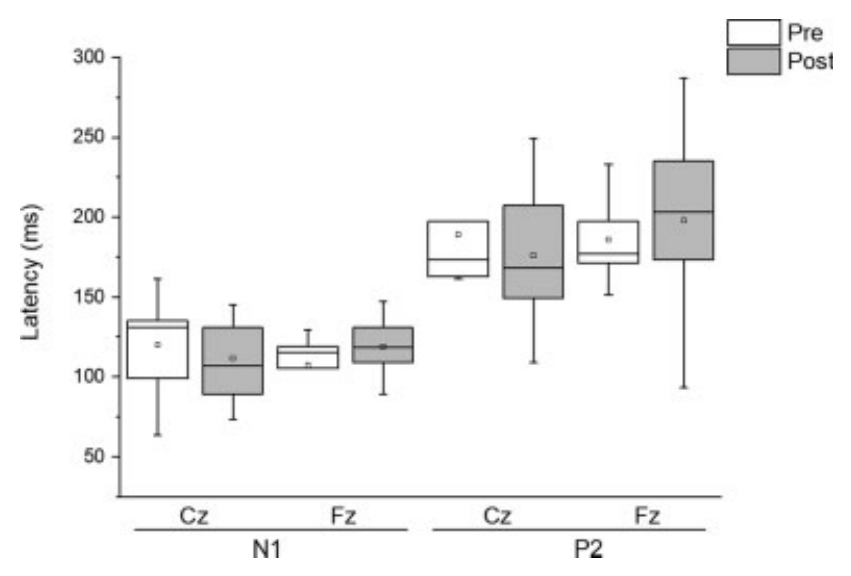

Fig. 1 Distribution of latency measurements of the $\mathrm{N} 1$ and $\mathrm{P} 2$ waves in the pre- (using $\mathrm{HA}$ ) and postphases (using $\mathrm{Cl}$ ), in the $\mathrm{Cz}$ and $\mathrm{Fz}$ electrode positions.

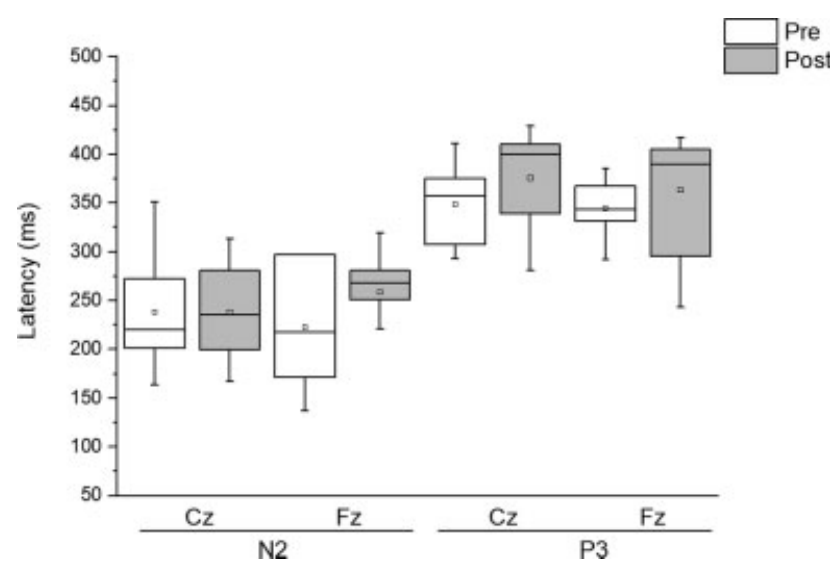

Fig. 2 Distribution of latency measurements of the N2 and P3 waves in the pre- (using $\mathrm{HA}$ ) and postphases (using $\mathrm{Cl}$ ), in the $\mathrm{Cz}$ and $\mathrm{Fz}$ electrode positions.

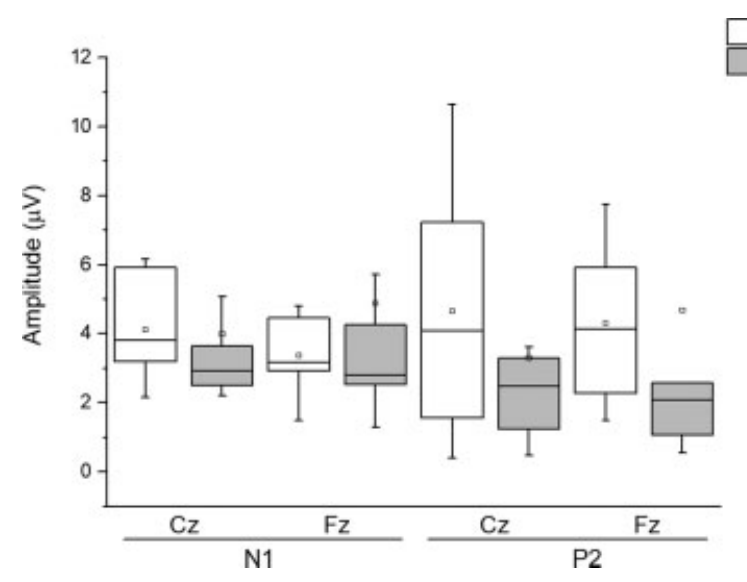

Fig. 3 Distribution of amplitude measurements of the $\mathrm{N} 1$ and $\mathrm{P} 2$ waves in the pre- (using $\mathrm{HA}$ ) and postphases (using $\mathrm{Cl}$ ), in the $\mathrm{Cz}$ and $\mathrm{Fz}$ electrode positions.

of the amplitude. Due to the objective of this study, there was an emphasis on the $\mathrm{P} 300$ cognitive potential. Therefore, we can observe that P300 mean latency values at $\mathrm{Cz}$ and $\mathrm{Fz}$ increase in the $\mathrm{Cl}$ phase. Amplitude levels decreased at $\mathrm{Cz}$ and increased at $\mathrm{Fz}$ during the transition from $\mathrm{HA}$ to $\mathrm{Cl}$.

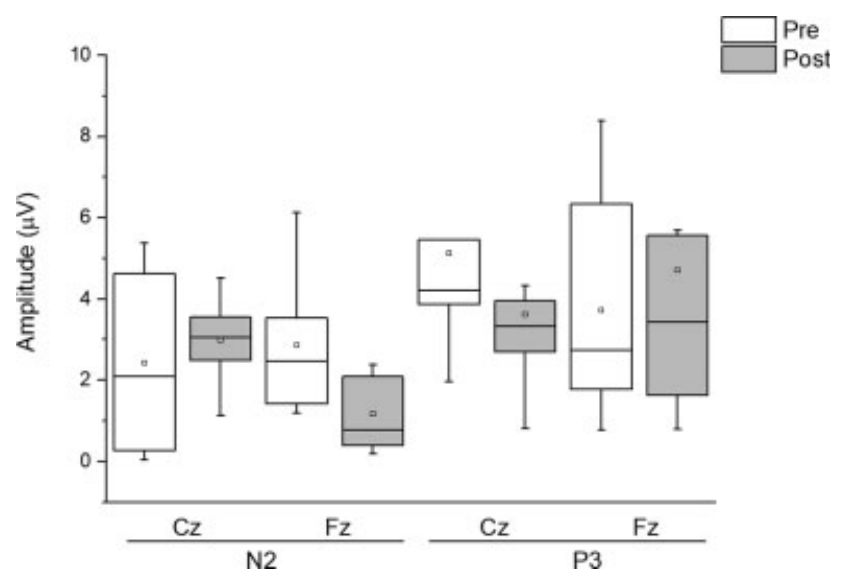

Fig. 4 Distribution of amplitude measurements of the N2 and P3 waves in the pre-(using $\mathrm{HA}$ ) and postphases (using $\mathrm{Cl}$ ), in the $\mathrm{Cz}$ and $\mathrm{Fz}$ electrode positions.

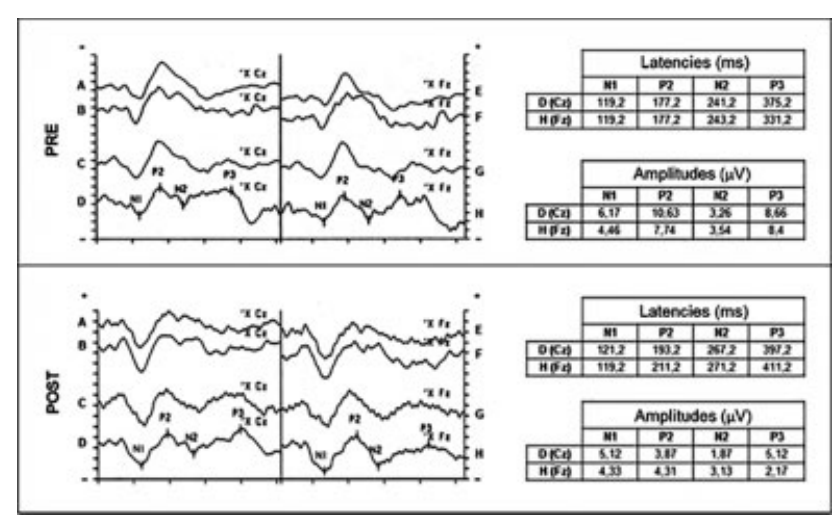

Fig. 5 Example of a record (with repetition) of the P300 test, about the present study, in the prephase (with $\mathrm{HA}$ ) and post (with $\mathrm{Cl}$ ). Letters $A, B E$ and $F$ are frequent registers. Letters $C, D, G$ and $H$ are infrequent registers, with electrode position in $\mathrm{Cz}$ and $\mathrm{Fz}$, respectively.

For both phases, wave morphology at $\mathrm{Cz}$ benefited the components' tracing ( - Fig. 5).

It is important to note that during training, before starting to effectively register potentials, some individuals showed more difficulty to detect the rare stimulus in the HA phase, needing more training time. Still in this phase, a few subjects could not distinguish two rare stimuli when presented in sequence, with a reduced time gap, that is, two or more rare stimuli in a row. In the meantime, that did not occur when they were in the CI phase, since they started to promptly respond and identify the rare stimuli even when presented with short time gaps.

Regarding the behavioral task during the exam, in the HA phase, five subjects showed immediate response to the onset of rare stimuli, six showed late response to the onset of rare stimuli, and one showed an incompatible response, that is, he raised his index finger in the absence of a rare stimulus. During the CI phase, 11 subjects showed immediate response to the onset of rare stimuli and only 1 showed late response, which indicates an overall better performance in the $\mathrm{Cl}$ phase. 


\section{Discussion}

Cochlear implantation is known to be the best option for profound hearing loss, ${ }^{16}$ as many studies show its effectiveness on the development of oral language and speech perception. ${ }^{17-19}$ Cochlear implant centers establish as one of the audiological criteria for candidates that, although they have effectively experienced using HAs, they are not benefitted by such device. Besides, if mean hearing thresholds in free field with HAs reveal no access to speech sounds, that indicates that those patients are $\mathrm{CI}$ candidates. ${ }^{20}$ With that being said, audiometry results from the first phase show correct indication of those subjects as $\mathrm{CI}$ candidates, with male predominance (58.33\%), which is also seen in other studies ${ }^{21,22}$ that show hearing loss is more frequent in male patients.

When correlating social and demographical variables related to hearing loss, it was verified that there is a strong positive correlation between the subject's current age and age at hearing loss (0.6526), current age and age when starting to use HAs (0.6450), and hearing loss onset age with age at the start of HA use (0.6816). Such result shows that this group of subjects received auditory stimulation through HAs, after hearing loss onset, and that is a crucial factor to consider for central auditory system activity maintenance. There was also a moderate negative correlation between the subject's age and mean hearing thresholds after at least 12 months of use (0.5912) ( - Table 4). This finding is also addressed in the literature, describing that an increased time of $\mathrm{CI}$ use results in an improved hearing ability (identified by decreased hearing threshold results) and performance in patients with postlingual hearing loss. Even at $\mathrm{Cl}$ activation, the ability to detect sounds is already noticeable and auditory recognition improves progressively, as well as speech comprehension, around 18 months after implantation.

We can verify that the data shown at $\boldsymbol{-}$ Table 1 reflect what has been happening in most audiological centers in Brazil, that is, individuals with early onset hearing loss ( 18.08 years old on average) waiting for a significant amount of time receive the intervention process (8.79 years of hearing deprivation on average) and an even bigger time when the time of HA adaptation is considered ( 26.58 years old on average). ${ }^{23,24}$ Those findings are probably explained by the demand of patients within the observed age range, who now represent $\sim 50 \%$ of individuals who seek treatment and electronic hearing devices in the study's country (Brazil). This demand conflicts with financial difficulties of public health programs.

It was evident in this research that mean hearing thresholds were better with $\mathrm{CI}$ than with HA. The comparison shows difference between averages of $43.92 \mathrm{~dB}$ HL and a considerable difference in word recognition of $40.22 \%$, equivalent to speech recognition improvement of over 10 words, showing there is a bigger benefit with the use of CIs (- Table 2). ${ }^{20,25}$ One study from $2004^{26}$ reported that, in the time between 6 and 12 months of $\mathrm{CI}$ use, some patients achieve their maximum hearing performance, while others keep evolving after 12 months.

Regarding etiology investigation, $50 \%$ of the subjects had an unknown cause of hearing loss and are under investigation, which agrees with previous researches..$^{21,22,26,27}$ Those studies indicate the need for genetic studies in cases of hearing loss with no apparent cause, so that we can get to a real etiological profile. Otosclerosis (16.67\%) showed the highest frequency among other etiologies (mumps, bacterial meningitis, ototoxicity, and mechanical trauma), which were present only once each (8.33\%). It was also noted that, when comparing average hearing thresholds with those of subjects with HAs and with Cls, only the subject with meningitis did not benefit from Cls and that is due to a reduction in the amount of spiral ganglion cells, which is a characteristic of the auditory system lesion caused by meningitis..$^{28,29}$

At the time of data collection, there was an equal distribution of $\mathrm{Cl}$ brands indicated to the patients, in a way that did not allow for a quantitative statistical comparison that could evaluate the association between the device brand and the subjects' responses to the tests.

Variables related to $\mathrm{CI}$ ( - Table 3 ), such as number of channels, pulse rate by channel and current $(\mathrm{Hz})$ did not present any significant difference when correlated to P300 amplitude and latency measurements, except for latency values correlated to $\mathrm{HA}$ and $\mathrm{CI}$ phases, which were increased. The latency of P300 does not depend on the physical characteristic of the acoustic stimulus, such as duration and intensity, but rather on proprieties related to the event, such as its probability, discrimination difficulty and stimulus novelty. Nonetheless, it is believed that there is a physiological P300 latency increase from the age of 15 years. ${ }^{30-33}$ In this study, comparisons of latency measures were made between the same individuals in different situations, over a short period of less than a decade. Therefore, it is believed that variations are related to the use of the electronic device.

P300 mean latency values increased at $\mathrm{Cz}$ and Fz during the CI phase (-Fig. 2), which wasn't initially expected, since the auditory benefit provided by CIs, verified through behavioral evaluations, is bigger than the benefit provided by HAs. Even with that increase, it was observed that mean latency values are within normality, with $348.80 \mathrm{~ms}$ at $\mathrm{Cz}$ and $344.42 \mathrm{~ms}$ at $\mathrm{Fz}$ during the HA phase and $375.37 \mathrm{~ms}$ at $\mathrm{Cz}$ and $363.02 \mathrm{~ms}$ at $\mathrm{Fz}$ during the $\mathrm{Cl}$ phase. ${ }^{6}$

This increase can reflect on the applied stimulus situation, which would activate more the parietal lobe region (P3b$250-500 \mathrm{~ms}$ component). This region is activated by the "oddball" stimulus and is connected to the activity of performing a task while receiving a stimulus. ${ }^{6}$ The $\mathrm{P} 300$ amplitude can be more related to the number of attention resources allocated to the stimulus and memory performance involved and represents brain's perception while receiving an important information.

The P300 amplitude can have a bigger association with the amount of attentional resources allocated to the stimulus and memory performance involved and represents brain's perception when receiving an important information. It is originated from different regions of the CANS that process different types of information, such as the frontal and central regions (P3a$250-280 \mathrm{~ms}$ ), and are related to the detection of stimulus novelty. The P300 latency reflects the time spent during stimulus cognitive processing and its amplitude is related to the amount of attention resources allocated during the stimulus. ${ }^{34}$ 
It is worth pointing out that some patients who had absent P300 responses in the HA phase started to show responses in the $\mathrm{CI}$ phase. A few studies also found an increase in P300 latency, justifying that the difficulty to discriminate stimuli can cause this latency increase, even if they respond correctly to the behavioral task. ${ }^{9,35}$ One of those studies reports that patients who always presented better sound discrimination also presented better latency values, that is, shorter latencies. ${ }^{9}$ Those findings suggest the possibility that direct electrical stimulation of the cochlea may not function as effectively as the auditory system does in conditions in which the cochlea is in its normal state, that is, not working simultaneously with an electric device.

When an individual is using HAs, a device that basically amplifies sound, the remaining cells are stimulated and the cochlea itself generates a nervous impulse, which is then transmitted to the CANS. This case is different from CI users, where there is an electricity transducer inserted in the cochlea to allow electric stimulation. This thought might explain latency delay at 12 months of $\mathrm{CI}$ use, and there is still the possibility that the cochlea needs more time to adjust to electrodes, which could bring different results in the future. Previous studies suggest there is information that codified sound delivered through CIs is different from the sound delivered by the normal cochlea, so it is likely that CI recipients' brains need highly charged auditory processing and, consequently, a higher effort during cognitive processing. ${ }^{35}$

In terms of amplitude, a decrease at $\mathrm{Cz}$ and an increase at Fz were observed from the HA phase to the $\mathrm{CI}$ phase. Amplitude values found were relatively low in both phases (HA phase $=5.13 \mu \mathrm{V}$ at $\mathrm{Cz}$ and $3.71 \mu \mathrm{V}$ at $\mathrm{Fz}$; CI phase $=3.68$ $\mu \mathrm{V}$ at $\mathrm{Cz}$ and $4.71 \mu \mathrm{V}$ at $\mathrm{Fz}$ ), and those values may be justified by the fact that the $\mathrm{CI}$ provides a lower discrimination field when compared with the cochlea itself. One study suggests P300's amplitude in CI patients is related to individual differences in their ability to discriminate, that is, patients with low discrimination capacity show lower amplitude levels. ${ }^{7}$

Although there was no significant difference between latency and amplitude results, it was noticeable that the wave morphology of frequent and rare stimuli during the test was more favorable to the tracing of the N1-P2-N2 complex and especially of the $\mathrm{P} 300$, in the rare register during the $\mathrm{CI}$ phase (-Figs. 1, 2, 3, and 4).

Considering the age factor, many studies suggest there is a variation of latency and amplitude measurements according to age; some studies show latency increase at around 1 to $2 \mathrm{~ms} /$ year, and amplitude decrease with an average rate of $0.2 \mu \mathrm{V} /$ year. ${ }^{36,37}$ In adults over 45 years old, latency increases $10 \mathrm{~ms}$ for each decade. ${ }^{38}$ One hypothesis is that participants in this research were 46.5 years old on average, which is a factor to consider concerning latency increase. However, in this study, the results' comparison was obtained in a single-subject manner, which is considered the most stable situation and, therefore, it should not be a considerable variable. It is also worth highlighting that there was a time span of 12 months between tests, so the age variable alone could not interfere in the difference found, that is, the latency increase (-Fig. 2). ${ }^{6,39,40}$
Another factor that could affect the results could be the fact that this research was conducted on the same patient at different time intervals, which is not a strong consideration, since literature has shown that latency variations are small under those circumstances. One study found mean retesting values of $10.50 \mathrm{~ms}(\mathrm{Fz})$ and $15.25 \mathrm{~ms}$ for female gender and $6.00 \mathrm{~ms}(\mathrm{Fz})$ and $5.83 \mathrm{~ms}(\mathrm{Cz})$ for male gender. ${ }^{37}$ Equivalent results were found in studies that demonstrated $\mathrm{P} 300$ latency measures test-retest reliability in normal adults ${ }^{41,42}$ suggesting that those patterns, observed for a long time, can reflect on the habituation of certain processes in the central nervous system. ${ }^{41}$

Early responses are usually related to the presented stimulus' sensation, perception and discrimination, while delayed responses are usually related to cognition and memory.

The exogenous complex, N1, P2 and N2, in a qualitative analysis, also presented increased latency values, especially at the Fz position, with a $35.53 \mathrm{~ms}$ difference for $\mathrm{N} 2,11.80 \mathrm{~ms}$ difference for P2 and $12.00 \mathrm{~ms}$ difference for N1. Amplitude values, as described in the literature, ${ }^{6}$ did not produce significant variations.

Statistical analysis showed that there was no relation between P300 and other variables; however, when related to latency values, in both phases, the result was $p=0.0545$. Although this result shows no significance, the number of participants in this study could lead to a bias, so one hypothesis is that a larger sample could give the result a different tendency.

Once the aim of the evaluation was to identify the P300 wave, the fact that the response procedure (raising the index finger instead of mentally counting) was modified did not interfere in the type of response. Some studies have concluded that, when comparing long latency potentials evaluation procedures, with different instructions regarding the perception of rare stimuli, the complex N1, P2, N2 did not change, although $\mathrm{P} 300$ showed a slight modification, which is precocious in the lower cognitive complexity process. ${ }^{12,43,44}$

A longitudinal assessment is important so that CANS changes in adults with CIs can be evaluated in an extended period and compared with CANS development in adults with normal hearing. Thus, studies with larger samples and longer time of observation are necessary for a better understanding of hearing disorders.

\section{Conclusion}

Behavioral and electrophysiological assessments have contributed to a better understanding of hearing performance in $\mathrm{CI}$ users. The participants showed a remarkable improvement of their hearing thresholds after 12 months of $\mathrm{CI}$ use, except for the patient with meningitis. Mean P300 latency levels increased after 12 months of $\mathrm{CI}$ use at $\mathrm{Cz}$ and $\mathrm{Fz}$, while mean amplitude levels decreased at $\mathrm{Cz}$ and increased at $\mathrm{Fz}$. There was a moderate negative association between age and mean hearing thresholds with CIs.

\section{Conflicts of Interest}

The authors have no conflicts of interest to declare. 


\section{References}

1 Budenz CL, Cosetti MK, Coelho DH, et al. The effects of cochlear implantation on speech perception in older adults. J Am Geriatr Soc 2011;59(03):446-453

2 Tefili D, Barrault GFG, Ferreira AA, et al. Cochlear implants: technological aspects and socioeconomic role. Braz. J. Biom. Eng. 2013;29:414-433

3 Goodin DS, Starr A, Chippendale T, Squires KC. Sequential changes in the P3 component of the auditory evoked potential in confusional states and dementing illnesses. Neurology 1983;33(09):1215-1218

4 Sutton S, Braren M, Zubin J, John ER. Evoked-potential correlates of stimulus uncertainty. Science 1965;150(3700):1187-1188

5 Kraus N, Mcgee T. Potenciais auditivos de longa latência. In: Katz J, ed. Tratado de audiologia clínica. São Paulo, SP: Manole; 1999:403-420

6 Mcpherson DL. Late potential of the auditory system. 2nd ed. San Diego: Singular Publishing Group; 1996

7 Kaga K, Kodera K, Hirota E, Tsuzuku T. P300 response to tones and speech sounds after cochlear implant: a case report. Laryngoscope 1991;101(08):905-907

8 Micco AG, Kraus N, Koch DB, et al. Speech-evoked cognitive P300 potentials in cochlear implant recipients. Am J Otol 1995;16(04): 514-520

9 Groenen PAP, Makhdoum M, van den Brink JL, Stollman MH, Snik $A F$, van den Broek P. The relation between electric auditory brain stem and cognitive responses and speech perception in cochlear implant users. Acta Otolaryngol 1996;116(06):785-790

10 Oviatt DL, Kileny PR. Auditory event-related potentials elicited from cochlear implant recipients and hearing subjects. Am J Audiol 1991;1(01):48-55

11 Franco GM. O potencial evocado cognitivo em adultos normais. Arq Neuropsiquiatr 2001;59(2-A):198-200

12 Simões HdeO, Frizzo ACF, Zanchetta S, Hyppolito MÂ, Reis AC. Variables in P300 recording: task type and electrode position. CoDAS 2016;28(04):355-361

13 Brasil. Portaria GM/MS N 1.278 de 20 de outubro de 1999. Aprova os critérios de Indicação e Contra-Indicação de Implante e as normas para Cadastramento de Centros/Núcleos para a realização de Implante Coclear. Brasília, out. 1999

14 Brasil. Portaria GM/MS N 793 de 24 de abril de 2012 (2012a). Institui a rede de cuidados à pessoa com deficiência no âmbito do Sistema Único de Saúde. Brasília, seção 1, p. 94-95, abril 2012

15 Brasil. Portaria GM/MS N 835 de 25 de abril de 2012 (2012b). Institui incentivos financeiros de investimento e de custeio para o Componente Atenção Especializada da Rede de Cuidados à Pessoa com Deficiência no Âmbito do Sistema Único de Saúde. Brasília, abril 2012

16 Miziara ID, Miziara CS, Tsuji RK, Bento RF. Bioethics and medical/ legal considerations on cochlear implants in children. Rev Bras Otorrinolaringol (Engl Ed) 2012;78(03):70-79

17 Geers AE, Nicholas JG, Sedey AL. Language skills of children with early cochlear implantation. Ear Hear 2003;24(1, Suppl)46S-58S

18 Angelo TCS, Bevilacqua MC, Moret ALM. Percepção da fala em deficientes auditivos pré-linguais usuários de implante coclear. Pró-Fono R Atual Cient 2010;22:275-280

19 Queiroz CAUF, Bevilacqua MC, Costa MPR. Estudo longitudinal da compreensão verbal de crianças usuárias de implante coclear. Rev CEFAC 2010;12:210-215

20 Blamey P, Artieres F, Başkent D, et al. Factors affecting auditory performance of postlinguistically deaf adults using cochlear implants: an update with 2251 patients. Audiol Neurotol 2013;18(01):36-47

21 Pupo AC, Balieiro CR, Figueiredo RSL. Estudo retrospectivo de crianças e jovens com deficiência auditiva: caracterização das etiologias e quadro audiológico. Rev CEFAC 2008;10:84-91

22 Calháu CMDF, Lima Júnior LR, Reis AMCS, et al. [Etiology profile of the patients implanted in the cochlear implant program]. Rev Bras Otorrinolaringol (Engl Ed) 2011;77(01):13-18
23 Nóbrega M, Weckx LLM, Juliano Y, et al. Aspectos diagnósticos e etiológicos da deficiência auditiva em crianças e adolescentes. Rev Paul Pediatr 1998;1:28-43

24 Pinto MM, Raimundo JC, Samelli AG, et al. Age at the diagnosis and in the beginning of intervention from hearing impaired children, in a public Brazilian hearing health service. Arq Int Otorrinolaringol 2012;16:44-49

25 Cullen RD, Higgins C, Buss E, Clark M, Pillsbury HC III, Buchman CA. Cochlear implantation in patients with substantial residual hearing. Laryngoscope 2004;114(12):2218-2223

26 Padilla Romero MJ, Sainz Quevedo M, Roldán Segura C. [Cochlear implant in postlingual adults with progressive hearing loss]. Acta Otorrinolaringol Esp 2004;55(10):457-462

27 de Nobrega M, Weckx LLM, Juliano Y. Study of the hearing loss in children and adolescents, comparing the periods of 1990-1994 and 1994-2000. Int J Pediatr Otorhinolaryngol 2005;69(06):829-838

28 Walch C, Anderhuber W, Köle W, Berghold A. Bilateral sensorineural hearing disorders in children: etiology of deafness and evaluation of hearing tests. Int J Pediatr Otorhinolaryngol 2000;53 (01):31-38

29 Guedes MC, Brito RV, Goffi-Gomez MVS, et al. Telemetria de resposta neural intra-operatória em usuários de implante coclear. Rev Bras Otorrinolaringol (Engl Ed) 2005;71:660-667

30 Green KMJ, Bhatt Y, Mawman DJ, et al. Predictors of audiological outcome following cochlear implantation in adults. Cochlear Implants Int 2007;8(01):1-11

31 Goodin DS, Squires KC, Henderson BH, Starr A. Age-related variations in evoked potentials to auditory stimuli in normal human subjects. Electroencephalogr Clin Neurophysiol 1978;44(04):447-458

32 Pfefferbaum A, Ford JM, Roth WT, Hopkins WF III, Kopell BS. Event-related potential changes in healthy aged females. Electroencephalogr Clin Neurophysiol 1979;46(01):81-86

33 Brown WS, Marsh JT, LaRue A. Exponential electrophysiological aging: P3 latency. Electroencephalogr Clin Neurophysiol 1983;55 (03):277-285

34 Polich J, Starr A. Evoked Potentials in aging. In: Albert MI, ed. Clinical neurology of aging. New York: Oxford University Press; 1983:149-177

35 Polich J. Updating P300: an integrative theory of P3a and P3b. Clin Neurophysiol 2007;118(10):2128-2148

36 Okusa M, Shiraishi T, Kubo T, Nageishi Y. Effects of discrimination difficulty on cognitive event-related brain potentials in patients with cochlear implants. Otolaryngol Head Neck Surg 1999;121 (05):610-615

37 Vesco KK, Bone RC, Ryan JC, Polich J. P300 in young and elderly subjects: auditory frequency and intensity effects. Electroencephalogr Clin Neurophysiol 1993;88(04):302-308

38 Reis ACB, Frizzo ACF, Isaac ML, et al. P300 in subjects with hearing loss. Rev Bras Otorrinolaringol (Engl Ed) 2014;81:126-132

39 Musiek FE, Baran JA, Pinheiro ML. Introduction to Case Studies in Neuroaudiology. In: Musiek FE, Baran JA, Pinheiro ML, ed. Neuroaudiology - Case Studies. Singular Publishing Group; 1994:1-5

40 Musiek FE. Aplicação de testes auditivos centrais: uma abordagem geral. In: Katz J, ed. Tratado de Audiologia Clínica. São Paulo: Manole; 1989:323-339

41 Oates PA, Kurtzberg D, Stapells DR. Effects of sensorineural hearing loss on cortical event-related potential and behavioral measures of speech-sound processing. Ear Hear 2002;23(05):399-415

42 Polich J, Howard L, Starr A. P300 latency correlates with digit span. Psychophysiology 1983;20(06):665-669

43 Sandman CA, Patterson JV. The auditory event-related potential is a stable and reliable measure in elderly subjects over a 3 year period. Clin Neurophysiol 2000;111(08):1427-1437

44 Machado SCS, Carvalho ACO, Silva PLG. Standard characterization of P300 in young adults. Rev Soc Bras Fonoaudiol 2009;14:83-90 